\title{
PREVENTION AND CRISIS MANAGEMENT
}

\author{
Ștefan POP \\ "Nicolae Bălcescu" Land Forces Academy, Sibiu, Romania \\ popstefan2000@gmail.com
}

\begin{abstract}
Crisis management should always be proactive and not just reactive. Every organization must engage in proactive crisis management by monitoring issues related to its business and to society in general, by assessing risks and developing a crisis communication plan. Proactive crisis management helps organizations anticipate a crisis before it occurs. This said, a great part of crisis management is reactive management, as it is about dealing with a crisis once it hits.
\end{abstract}

\section{Keywords: crisis, tension, management}

\section{Introduction}

Having in mind that crisis management should always be proactive, we will furthermore understand what the prevention concept really means and what we have to do in order to help people not to make mistakes. If we try to give a prevention definition, we have to underline that there are several theoretical concept. So DEX says that "to prevent"means to draw attention the negative consequences some actions would have; to previously inform ; to warn ; to praise or to have precocious measures to avoid any unpleasant aspect ; to see before happening ; to fulfill somebody's desires by guessing them / from prevenir in French and praevenire in Latin. It also can means to use people's awareness before acting on the consequences their actions would have (usually aiming to stop those actions) ; to inform before having asked; to announce before being too late ; to warn in a civilized way.

"I warn you,dear Petre Ivanescu : you find yourself in front of a serious danger" [1] "I had warned you. I am not good to be a referee." [2] She warned him as soon as she had heard that he wanted to get married". "
Adela had done the most important step in her life without having been able to tell me about it" [3]. To think about all possible solutions and to do whatever necessary actions before their starting moment, to try everything just to avoid danger." [4] To stop the union of two enemy armies, fighting the weakest first and the strongest afterwards is one of the most beautiful operation concerning military art [5] To fulfill somebody's desires before they have been revealed by means of words: "What are you doing there? I help your unspoken wishes to come true: I open this door" [6] Preventive activity is not only a theoretical concept because it is not, first of.all, in all every days life's domains.

\section{General considerations}

Any kind of actions which could hurt an isolated person or society on its whole, gives birth to a preventive defense reaction that generates taking some anticipative measures in order to stop the generating cause in further producing or repeating. Any kind of preventive actions organized either by individuals or groups suppose both less efforts and costs than solutions to consequences. If that cause which 
determined a specific phenomenon is followed by own effect it is much more difficult to solve damaged aspects. For instance if we speak about a murder action followed by the victim's death, nothing can be solved after it because the killer gets the right punishment while the victim never comes to life again. If by appropriate taken measures, we prevent the murder commitment those tragic consequences do not appear any longer. It's about the same when speaking of society's level: to take preventive measures which stop generating causes to produce their effects is more beneficial and cheaper than the produced effect. Furthermore, preventing acts much more deeper and just really having an influence on the actions wholeness, while fighting work develops only in relation to each specific case and following the road of bad behavior recognition.

\section{Causes, infraction and infractionality}

The preventing activity is highly linked to the explanation of the infraction causing origins. To prevent means to act in advance in view of stopping a probable cause process to appear suspecting that it could lead to the violation of social behavior rules. This also implies to know the cause which could determine violating some social living rules, in order to find out what exactly should be prevented. If we don't have such helpful information, the action would take place into a anarchical resultless way.

The cause of any executed infraction could never be identical to the cause of the material result production (if that infraction does suppose such a material result ) as shown in the worn content. Regarding the former convention, we have in mind the main causal process which has as a direct consequence violation of any form or disposition of a penal law ( criminalistics aspect ; while speaking about the latter connotation, we think about a secondary causal process and we are interested to establish the penal responsibility ( penal aspects). In the first case, we follow the biological, psychological social factors to explain what exactly determines the subject to violate penal law. Thus, the subject's action appears as an effect of some determining causes. In the second case, we study to clarify the causal link between the subject's material activity and the find resulted product. In such a situation, the subject's action appears as being the cause while the result asked by the law is called effect. By cause, as seen in this context we name all factors which determine infraction commitment. These factors that favour an infraction commitment are circumscribed in the condition concept sphere.

The way into which causes and conditions mix in the final result produced by a man's actions approves to be extremely complex, both of them being practically inseparable through a volitive act. That why we frequently we use the idea of criminogen factors is the meaning of objective elements which interfere in an infraction commitment. Some criminologist use the motion of condition in a larger meaning ( more precisely any kind of happening without which a certain behavior wouldn't have developed and externalized ) thus giving up at the difference between the cause and condition. the cause analyzed from a subjective point of view, is also named infraction mobile by some authors for example O. Kinberg

For an etymological point of view, no matter what exterior manifestation, even that of an isolated person, is considered " a phenomenon" ( in Greek language phenomenon means "what appears", "what is outside manifested" ). Giving that complete and systematic analysis of the infraction causality as an individual action does not make the objective of the present topic, we won't insist on it only within the minor limits enough to the subject comprehension but having in mind to deeply develop it in another work especially destined to this important problem.

Crisis are complex phenomenon which can affect by their development not only individuals but also the whole political 
system, the entire economical lives they can personalize financial - banking systems, they can block social structure as well as affect international relationships.

At present, there is neither an elaborated nor or unanimously accepted theoretical to exactly define the motion of crisis but only an authors unanimity who try to name it. So, in more authors opinion crisis could be defined as being:

-manifestation of economical, political, social difficulties, period of tension, troubles, attempts sometimes decisive and dramatical ones which that occur in society ; deep lack of merchandise, time, work free

- critical, climbing moment in the evolution which proceeds healing or intensifying of an illness, sudden appearance of a hidden sickness or of an on-the-spot access in case of a chronical illness.

- tension moment of great soul's sufferance ( from French : crise source : EXD 1998 added by IoanSoleriu)

Crisis is defined as a period characterized by intense accumulation of difficulties by conflictual tension rising in a system dynamics, the leading to difficulties in its normal functioning thus being pressed powerful pressions towards changesdefinition given by C. Zamfir and L.Vlesceanu in their coordinated Sociology Dictionary.

The Explicative Dictionary of the Romanian Language mentions the crisis motion as being " manifestation of economical, political, social difficulties, period of tension among groups of states. This is a logical conception which put the basis to the leadership nowadays world's destinies.Unfortunately, it actually reveals more and more its ability limits when thinking about correspondingly solving people's interests societies problems and the natural equilibrium.

In order to become able to efficiently solve present crises, we have to understand their origin, their nature, their typology and their specific periods.

There are four important crises sources :

- at the individual level
- at the organization level

- at the society level

- at the system level

From the point of view of the military science, when analyzing a crises evoluti, we'll have a scale from peace to as the following : table, peace, unstable peace, crisis, war, reconstruction, post conflict crisis, reconciliation. Limits among these periods could be traced only by operational reasons, real ones among them being extremely vague. [7]

At this level, crisis is defined as being a scale of the conflict, characterized by tensional conflicts among implied army forces such as: the case of the cold war's relationships between the United States of America and The Soviet Union in the '50ties ; relationships between North and South Korea. After the war period, the postconflictual crises is present. Passing from one level to another within a certain crisis could be determined by the following factors of confusion, of trouble, of actions sometimes violent which take place into society.

R. Boudon and his collaborators present crisis in another dictionary in 1996 as being that moment when controlling mechanisms and a certain group's identity are tested by strong conflicts, generally not forseen, period considered as transitory, dangerous and waiting for an uncertain resolution. [8]

\section{Causes, forms of manifestation and types of crises}

We can't speak about any crisis as long as we don't know its origin as well as the causes that have generated it. Any person could interact with crises depending on their causes and getting out of them either by winning or loosing something. If the entire community does not treat very seriously any appeared crisis in order to solve all its conflicts, everybody could live important damages.

That's why throughout historical times, mankind understood the necessity that this fight can't be won otherwise than by unificant forces and actions aimed to stop 
conflictual situations. Following society's evolution, mankind understood that the only concentrated action of stopping crises is no longer sufficient, a careful preventing action is necessary in order to evaluate moments of appearance besides its solving strategy.

When we speak, there are great inequality concerning social and cultural development not only among different states but also the intensity and the number of the people's complaints, different perceptions and attitudes of the implied forces ones towards the others emotional intensity, psychological investment in forces, positions, the level of the mobilization and political organizations, the collision between those forces leaders and the group's members the density of hostile behaviours, the threatening stade or the use of arms, the number of each involved part's sustainers.

During a crisis period environment could be characterized as following:

- disbelief, polarizing social and political differenciesarms usage development of changing actions, of some isolated actions, even not well organized having a low-levelled violence character, intergroups repression, insurgence, systematic violation human rights, national mobilization, and so on.

In such a case the action time is shortprimary objectives focusing on reducing and controlling specific means of coencision which could be used during evident conflicts to block violent actions, to reduce tensions, to frozen hostilities, to solve political disputes, to maintain security, primary safety security by level to create some non-violent means to come out from the crises.

Past conflict crises can also manifest by the following forms:

-great number of victims, low-levelled political support for armed forces,psychological institutional infrastructure destruction, lacs of social services, political instability, political transition.
The most important objectives in this situation must be done at once but also on a long term taking into consideration:

- going back to normal behavior speaking about action an inter-actions of the conflictual sides, achieving the reform and economic re-structure, the security services reform, rehabilitation of social service sector and of the institution.

\section{Phases characteristics and effects of the crises}

Any crises appears on a time, having a specific evolution, according to the domain it appear. Any crisis is for most of the times proceeded by a preliminary period during which the conflict grows higher and higher and which announces the appearance of the crisis. From this cause, the so-called critical phase surprises and shatter the normal order of the system. The way in which the system's management founds solution to the crisis process can shorten or longer the crisis time. We may find ourselves in front of three phase during crisis evolution : before-the-crisis, preliminary phase, the effective crisis ( the critical phase) and after-the-crisis ( the reconstructing phase ) Before-the-crisis ( preliminary crisis begins on the very moment when destructions appear against the usual interactions of a system's elements, destructions which can constitute real threats for the system's objectives. Thisphase determines a state of managerial vigilence accompanied by an atmosphere of tensional excitement.

The effective crisis ( the critical phase ) could manifest through violence or calm could be from a shorter to a longer period of time, waited or coming by surprise. During this phase, the following events take phase.

In case of financial, econonomic, energetic or prime matters crisis, violent transformations occur in the normal functioning of all system which deeply affectcitizens life under all possible aspects such as education, incomes, work places, health, etc. Specialized expertsinterference is immediately needed in order to offer 
fundamental anticrisis plans to be decisional making political factors ; problems connected to fundamental values such as : freedom, democracy, national identity, territorial identity, statal sovereignity are the so-called declared nontangible problems ; they can't be negociated, they lead to army conflicts, generally speaking; in the case of geopolitical crisis during the critical period, fundamental values and institutions of thestate are put into danger because of the armed interactions while some of the of the specialized structures focused on achieving national sefaty and security become or can become overcome by the created crisi solutions.

At an organizational level, the dynamics of world's powerful relationships modify the poles role so that the dominant one becomes from self-protector hostile, arbitrary, incoherent while the dominated pole does not anymore recognize the formers authority and supremacy, the dezintegration of the dominatig pole's power relantionships has a natural consequence individual colapses, depressions, alchoolism, violence and, in the end, the social exclusion. During te critical period, the management has to face diverse challenges and as a direct consequence any crisis effects could be totally different because they are strictly connected to the management's ability of solving the conflict.

\section{Post-crisis ( he rebuilding period)}

We can say that the critical period disappeared the very moment when either crisis implied actors declare by themselves its overpassed point due to the fact that usual practices have been retaken within a certain regularity and all confrountations had stopped or the system broke down and a new one is to be prejected at an waiting horizon.

In any of these two cases, the new system to be born, still keeps crisis secrets till its renaissance day, after having passed through an invertion period. There re also situations in which during the rebuilding period a new project could appear, a new beging within which the dynamics of the power relationships produce a change by linking new energies into a coherent practice.

\section{Conclusions}

After a crisis, we could say that the power dominant pole, based on new principles, gets a minimum percentage of accepting and using those energies into practice. The way into which the dominant pole of the system is recepted by the dominated one, moderates a new situation, the organizational climate. Both poles pass during this period from influencing to negociations. The evolution analysis of any conflictual situation in a crisis case shows that its appearance supposes a step-by-step accumulation of tension during time. To sustain this, more phases of the conflictual situation could be put into evidence and all of then are characterized by a series of challenges to which implied conflict parts have to face and solve, too.

\section{References}

[1] Agarbicean, S.P. 238, https://dexonline.ro/definitie/preveni

[2] Sebastian T.96, https://dexonline.ro/definitie/preveni

[3] Ibraileanu A, 33, https://dexonline.ro/definitie/preveni

[4] Rebreanu R.I.137, https://dexonline.ro/definitie/preveni

[5] Hasdeu I.V.133, https://dexonline.ro/definitie/preveni

[6] Stefan Pop, "Crimiology-Preventing and International Police Cooperantion", Ed Sitech 2013,

[7] Explicative Romanian Dictionary, 1998

[8] R.Boudon and collaboratores, Dictionary 1996. 